BMJ Open

Sport \&

Exercise

Medicine

\title{
High-intensity interval training to improve fitness in children with cerebral palsy
}

\author{
Reidun Lauglo, ${ }^{1}$ Torstein Vik, ${ }^{2}$ Torarin Lamvik, ${ }^{3}$ Dorthe Stensvold, ${ }^{4}$ \\ Ane-Kristine Finbråten, ${ }^{2}$ Trine Moholdt ${ }^{4,5}$
}

To cite: Lauglo R, Vik T, Lamvik T, et al. High-intensity interval training to improve fitness in children with cerebral palsy. BMJ Open Sport Exerc Med 2016;2: e000111. doi:10.1136/ bmjsem-2016-000111

- Prepublication history for this paper is available online. To view these files please visit the journal online (http://dx.doi.org/10.1136/ bmjsem-2016-000111).

Accepted 26 March 2016

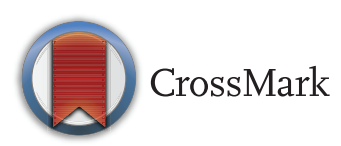

\footnotetext{
${ }^{1}$ Rosenborg Physiotherapy Clinic, Trondheim, Norway ${ }^{2}$ Department of Laboratory Medicine, Children and Women's Health, NTNU, Norwegian University of Science and Technology, Trondheim, Norway ${ }^{3}$ Department of Orthopedic Surgery, St. Olav's Hospital, Trondheim, Norway ${ }^{4}$ Department of Circulation and Medical Imaging, NTNU, Norwegian University of Science and Technology, Trondheim, Norway ${ }^{5}$ Women's Clinic, St. Olav's Hospital, Trondheim, Norway
}

Correspondence to Dr Trine Moholdt; trine.moholdt@ntnu.no

\section{ABSTRACT}

Aim: To evaluate effects of high-intensity interval training (HIT) on aerobic exercise capacity, quality of life, and body composition in children with cerebral palsy (CP).

Methods: This was a baseline control trial. Children with CP, Gross Motor Function Classification System (GMFCS) levels I-IV, and age 10-17 years were included. The primary outcome, peak, and submaximum oxygen uptake $\left(\mathrm{VO}_{2 \text { peak }}, \mathrm{VO}_{2 \text { submax }}\right)$ were measured at enrolment to the study (T0), after a pretraining period (T1), and after HIT (T2). Secondary outcomes were quality of life assessed with the KINDL questionnaire, and body composition measured using whole body dual-energy X-ray absorptiometry scanning. The exercise was performed on treadmills and consisted of 24 sessions, each with a total of 16 min of exercise at $>85 \%$ of maximal heart rate. Results: 20 children were included and 6 children dropped out. $\mathrm{VO}_{2 \text { peak }}$ increased by $10 \%$, from a median of $37.3(31.0-40.1)$ to $41.0(36.6-48.5) \mathrm{mL} / \mathrm{kg} / \mathrm{min}$ from $\mathrm{T} 1$ to $\mathrm{T} 2(\mathrm{p}<0.01) . \mathrm{V}_{2 \text { submax }}$ did not change; thereby, the percentage oxygen utilisation was reduced. Body composition was unchanged. Parent-reported quality of life improved, whereas quality of life reported by the children did not improve.

Conclusions: Aerobic exercise capacity improved and per cent utilisation of $\mathrm{VO}_{2 \max }$ declined after HIT in children with CP. Therefore, HIT can be a time efficient way to improve maximal capacity, and increase energy reserve in this patient group.

Trial registration number: NCT00965133.

\section{INTRODUCTION}

Children with cerebral palsy (CP) have lower aerobic exercise capacity, and a higher oxygen cost for activities of daily living compared with typically developing children, ${ }^{1}$ and the oxygen cost increases with increasing disability. $^{2}$ The consequences can be fatigue and maintenance of low physical activity level. ${ }^{3}$ Thus, interventions that improve peak oxygen uptake $\left(\mathrm{VO}_{\text {2peak }}\right)$ may result in lower ambulatory oxygen cost in proportion to

\section{What are the new findings?}

- Aerobic exercise capacity increased by $10 \%$ after 24 sessions of high-intensity interval training in children with cerebral palsy.

- Quality of life was improved after a period of exercise training, according to the children's parents.

- Also children with Gross Motor Function Classification System level III and IV were able to walk on a treadmill with the use of a partial body weight support system.

total energy amount, and hence more energy resources are available for daily activity.

More research is needed to identify which exercise programmes may be most effective in improving aerobic exercise capacity in children with CP. High-intensity interval training (HIT) has repeatedly been shown to improve $\mathrm{VO}_{\text {2peak }}$, and to cause superior beneficial physiological and health-related changes in healthy and various diseased populations. ${ }^{4} 5$ However, how HIT may be implemented as part of the care for children with CP is yet not assessed. We also need evidence about the effects of exercise training on quality of life and body composition in children with CP. ${ }^{67}$

The primary aim of this study was to investigate the effects of HIT on $\mathrm{VO}_{2 p e a k}$, and oxygen cost of a submaximal effort in children with CP. Secondary aims were to evaluate the effects of HIT on quality of life and body composition, as well as to assess the feasibility of HIT in this population. We hypothesised that HIT would improve the $\mathrm{VO}_{\text {2peak }}$ of children with $\mathrm{CP}$, subsequently reducing their oxygen cost of walking or running, and that HIT would improve the children's quality of life and their body composition. 


\section{METHODS}

\section{Study design}

This was a baseline control trial, with tests at three different points of time: at enrolment to the study (T0), after a pretraining baseline period of 4 weeks (T1), and at the end of HIT (T2) (figure 1). Between T0 and T1, the children continued with regular physical activity and between test $\mathrm{T} 1$ and T2, they did HIT on treadmills. Aerobic capacity and quality of life were measured at all three test points, while body composition was measured at T1 and T2. A partial body weight support system was used in children $(n=4)$ who struggled to maintain balance or upright position on the treadmill. The children who normally used orthopaedic shoes or orthoses for daily activity used these during testing and training.

\section{Participants}

Inclusion criteria: Children with CP, Gross Motor Function Classification System (GMFCS) level I-IV, age 1017 years, living in Mid-Norway. Exclusion criteria: Not able to perform any of the test procedures and the exercise training. Sample size. To be able to detect at least a $10 \%$ improvement in $\mathrm{VO}_{\text {2peak }}$ following $\mathrm{HIT}$-an increase considered to be of clinical relevance-a sample size calculation revealed that a minimum of 9 participants had to be included in the study to obtain $80 \%$ statistical power with an $\alpha$ of 0.05 . We invited 24 children to participate in the study to take into account that some of the children may be unable to perform the tests and the exercise intervention, as well as possibly dropout during the training period. The participants were recruited through physiotherapists and physicians who considered them able to perform treadmill exercise testing and training. The participants and their parents signed a written informed consent form prior to participation. The study was approved by the Regional Committee for Medical and Health Research, and was in accordance with the ethics standards of the Helsinki Declaration.

\section{Exercise training}

The intervention consisted of HIT for walking or running on a treadmill. Each session started with warming up for 5-10 min at low-to-moderate intensity. Our primary goal was for the participants to perform four times $4 \mathrm{~min}$ intervals at $>85 \%$ of their maximal heart rate $\left(\mathrm{HR}_{\max }\right)$, with active breaks at moderate intensity of about $70 \%$ of $\mathrm{HR}_{\max }$ in between and at the end. However, the protocol was individualised so that all participants did intervals of 1/2-4 min of high-intensity exercise, with a total of $16 \mathrm{~min}$ of high-intensity exercise each session. If the high-intensity intervals were shorter, so were the moderate-intensity break periods. Four children used a partial body weight support system (FreeSpann with Likorall 200 and vest) during exercise training. The exercise sessions were performed 2-4 times per week until a maximum of 24 sessions were completed. All exercise sessions were supervised by a physiotherapist. The reason for different duration of the intervals, as well as different frequency of training during the intervention period, was that the protocol had to be individualised based on each child's abilities for accomplishment and time schedules.

\section{Outcome measures}

The primary outcome measures were $\mathrm{VO}_{2 \text { peak }}$ and oxygen cost of an individually standardised submaximal effort $\left(\mathrm{VO}_{2 \text { submax }}\right)$. At each time point, the participants did a maximum effort exercise test on a treadmill (Woodway, Wisconsin, USA) with direct measurements of oxygen uptake (Metamax II, Germany). Heart rate was monitored throughout the test (Polar, Finland).

Peak oxygen uptake: After warming up for $10 \mathrm{~min}$, the participants walked or ran with increasing load until subjective exhaustion, or due to standard clinical criteria. ${ }^{8}$ If the respiratory exchange ratio at the end of the test was $\geq 1.05$ and Borg scale ${ }^{9}$ score was $\geq 17$, we regarded the test results as a true $\mathrm{VO}_{2 \text { peak }}$. The $\mathrm{VO}_{2 \text { peak }}$ was

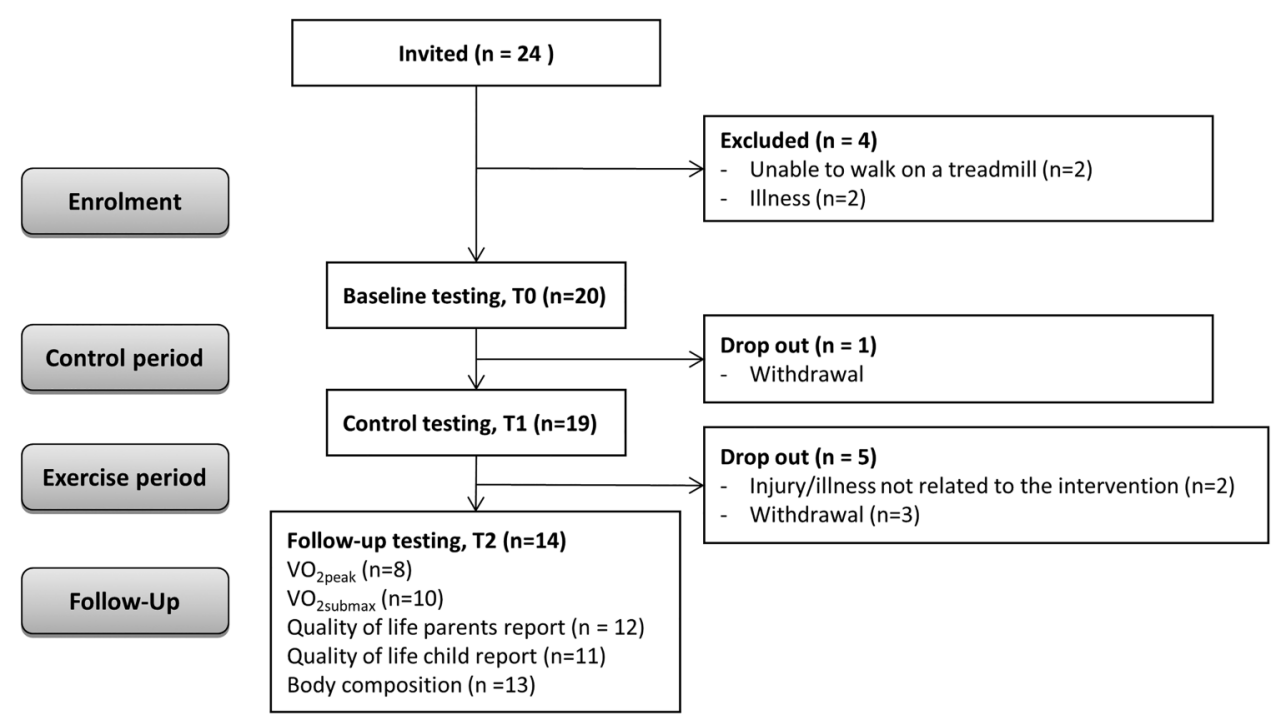

Figure 1 Flow chart of participants and study design. 
averaged within $30 \mathrm{~s}$ where the highest oxygen uptake was sustained. Only participants reaching $\mathrm{VO}_{2 p e a k}$ were included in the analyses of $\mathrm{VO}_{2 \text { peak }}$ and percentage utilisation of $\mathrm{VO}_{2 \text { peak }}$ at the submaximal effort test.

Submaximal effort test: The participants walked or ran at a steady rate for $4 \mathrm{~min}$ at a submaximal (standardised for each participant at all test times) level. We measured oxygen uptake and heart rate during this time, and used the average of the last minute to estimate submaximal heart rate and $\mathrm{VO}_{2 \text { submax }}$. The fractional oxygen cost of the submaximal effort was then calculated as the percentage of $\mathrm{VO}_{2 \text { peak }}$.

Health-related quality of life. Health-related quality of life was registered by self-report (age adapted), and from parents (proxy version) using the Norwegian version of the KINDL questionnaire. ${ }^{10}$ This is a measure developed to assess quality of life in children and adolescents both in the general population and in clinical settings. The questionnaire consists of 24 items divided into six subscales, where each item addresses the child's experiences over the past week. Mean item scores were calculated for the total scale and all subscales, and transformed to a scale from 0 (very low) to 100 (very high) quality of life.

Body composition: Total mass, fat mass, lean mass, and bone mass were assessed by whole body dual-energy X-ray absorptiometry (DXA) through scanning (Hologic Discovery) in the supine position by a trained clinical technician.

\section{Statistical analyses}

The statistical analyses were performed using the statistical software package SPSS, V.19. A $p$ value $<0.05$ was considered statistically significant (two-tailed). Children who did not use a body weight support system and reached $\mathrm{VO}_{2 \text { peak }}$ at all assessment points were included in the primary analysis of change in $\mathrm{VO}_{2 \text { peak }}$ and percentage utilisation of $\mathrm{VO}_{2 \text { peak }}$ at the submaximal effort test. Children who did not use a body weight support system and who could perform the submaximal effort test were included in the analysis of absolute $\mathrm{VO}_{2 \text { submax }}$ and submaximal heart rate.

All children with available data for quality of life and body composition before and after the exercise training were included in the analyses of these outcome measures. As this was a pilot study with a low number of participants, we used the non-parametric Friedman's test to compare the outcomes at different time points. When the test was significant, we did post hoc tests to decide which time point was different from the others. We did not adjust for multiple comparisons. Data are presented as median values with $I Q R$.

\section{RESULTS}

Of the 24 invited, four children were excluded due to limited motor control or illness, and hence lack of ability to perform the intervention training. One participant dropped out before $\mathrm{T} 1$, and an additional five dropped out before the testing at T2 (figure 1). Age and sex of the participants, as well as CP subtype and level of motor functioning are outlined in table 1 .

Duration of the exercise training period and number of sessions per participant, as well as what analyses each participant was included in, are outlined in table 2. No adverse events were registered during the exercise testing and training.

\section{Peak oxygen uptake}

$\mathrm{VO}_{2 \text { peak }}$ increased by $10 \%$ after the HIT period (T1T2), from $37.3(31.0-40.1) \mathrm{mL} / \mathrm{kg} / \mathrm{min}$ to $41.0(36.6-$ 48.5) $\mathrm{mL} / \mathrm{kg} / \min (\mathrm{p}<0.01)$ (table 3$)$.

\section{Submaximal effort test}

There was no significant difference in $\mathrm{VO}_{2 \text { submax }}$ between time points $(p=0.12)$. There was a significant difference between time points in submaximal heart rate $(\mathrm{p}=0.03)$, with a decrease of 10 beats $/ \mathrm{min}$ between $\mathrm{T} 1$ and $\mathrm{T} 2$ (table 3). The per cent utilisation of $\mathrm{VO}_{2 \text { peak }}$ at the submaximal effort test decreased significantly between $\mathrm{T} 1$ and T2 (table 3).

\section{Health-related quality of life}

In parents-reported quality of life, there was significant difference over time in total score $(p=0.04)$ and in the self-esteem subscale $(\mathrm{p}=0.02)$ during the study period. Post hoc comparisons showed that the difference was significant between $\mathrm{T} 1$ and $\mathrm{T} 2$ for both of these measures ( $p=0.01$ for both). There were no significant changes $(\mathrm{p}=0.10)$ in child-reported quality of life. The median child-reported score on the total scare was 64.5 (55.378.6), whereas the median parent-reported score on the total scale was $63.0(57.5-73.5)$.

\begin{tabular}{ll} 
Table 1 & Baseline characteristics of participants \\
\hline Boys/girls (number) & $11 / 9$ \\
Age, years & $14(13-16)$ \\
Weight, $\mathrm{kg}$ & $51.0(37.3-63.8)$ \\
Height, cm & $160(150-166)$ \\
BMI, $\left(\mathrm{kg} / \mathrm{m}^{2}\right.$ ) & $19.7(18.4-23.8)$ \\
GMFCS level (number of participants) & \\
I & 8 \\
II & 4 \\
III & 3 \\
IV & 5 \\
CP subtype (number of participants) & 9 \\
Hemiplegia & 4 \\
Quadriplegia & 3 \\
Diplegia & 3 \\
Dyskinetic & 1 \\
Ataxic & \\
Values are median (IQR) if not otherwise stated. \\
BMI, body mass index; CP, cerebral palsy; GMFCS, Gross Motor \\
Function Classification System.
\end{tabular}


Table 2 Number of training sessions, weeks of exercise, and the analyses each participant was included into

\begin{tabular}{|c|c|c|c|c|c|c|c|c|c|c|c|c|c|c|}
\hline \multirow{2}{*}{$\begin{array}{l}\text { Participant } \\
\text { number } \\
\end{array}$} & \multicolumn{10}{|c|}{ Participants included in statistical analyses } & \multicolumn{4}{|c|}{$\begin{array}{l}\text { Participants using } \\
\text { PBWSS }\end{array}$} \\
\hline & 1 & 2 & 3 & 4 & 5 & 6 & 7 & 8 & 9 & 10 & 11 & 12 & 13 & 14 \\
\hline Sessions & 23 & 24 & 18 & 22 & 23 & 23 & 11 & 23 & 24 & 24 & 24 & 22 & 24 & 24 \\
\hline Weeks & 10 & 8 & 9 & 9 & 12 & 12 & 5 & 12 & 8 & 9 & 12 & 12 & 9 & 9 \\
\hline $\mathrm{VO}_{2 \text { peak }}$ & $x$ & & $x$ & $x$ & $x$ & $x$ & & $x$ & $x$ & $x$ & & & & \\
\hline $\mathrm{VO}_{2 \text { submax }}$ & $x$ & $x$ & $x$ & $x$ & $x$ & $x$ & $x$ & $x$ & $x$ & $x$ & & & & \\
\hline QoL parent & & $x$ & $x$ & $x$ & $x$ & $x$ & $x$ & $x$ & $x$ & $x$ & & $x$ & $x$ & $x$ \\
\hline QoL child & & $x$ & $x$ & $x$ & $x$ & $x$ & $x$ & $x$ & $x$ & $x$ & & & $x$ & $x$ \\
\hline DXA & $x$ & $x$ & $x$ & $x$ & $x$ & $x$ & $x$ & $x$ & $x$ & $x$ & $x$ & & $x$ & $x$ \\
\hline
\end{tabular}

DXA, dual-energy X-ray absorptiometry; PBWSS, partial body weight support system; QoL child, child-reported quality of life; QoL parent, parent-reported quality of life; $\mathrm{VO}_{2 \text { peak }}$, peak oxygen uptake; $\mathrm{VO}_{2 \text { submax }}$, submaximal oxygen uptake.

\section{Body composition}

There was a trend towards increased lean mass between $\mathrm{T} 1$ and $\mathrm{T} 2(\mathrm{p}=0.05)$, otherwise no changes in body composition (table 4$)$.

\section{DISCUSSION}

Our main findings were significantly improved $\mathrm{VO} 2_{\text {peak }}$ and lower per cent utilisation on a submaximal effort test in children with CP after HIT. This means that these children had an improved aerobic exercise capacity and increased energy reserve after the intervention. We found, however, no changes in body composition and only minor changes in parent-reported quality of life after the exercise period.

In typically developing children, $\mathrm{VO}_{2 \text { peak }}$ has been reported to improve by $8-10 \%$ after aerobic training. ${ }^{11}$ Our results are in line with this. There are, so far, limited data from controlled clinical trials on the effect of exercise training on $\mathrm{VO}_{2 p e a k}$ in children with CP. Nsenga et $a l^{12}$ recently found a $22 \%$ improvement in $\mathrm{VO}_{\text {2peak }}$ following 8 weeks of aerobic exercise training on cycle ergometer (3 weekly sessions of 30 min with an intensity of $50-65 \%$ of estimated $\left.\mathrm{VO}_{2 \text { peak }}\right)$. As opposed to our study, the participants' peak heart rate was higher at the follow-up testing than at baseline, implying that they also increased their level of exertion at the second test. Unnithan et $a l^{13}$ obtained $18 \%$ higher $\mathrm{VO}_{2 \text { peak }}$ after 3 months of combined endurance and strength training
(3 weekly sessions of 70 min with an intensity of $65-75 \%$ of predicted $\mathrm{HR}_{\max }$ ). Please note that the participants in our study only exercised for about $35 \mathrm{~min}$ each time and for fewer sessions in total. We argue that finding timeefficient exercise programmes is particularly important for children with CP as they often spend more time on activities of daily living and different therapeutic interventions than their non-disabled peers.

The absolute oxygen uptake at a submaximal effort test was unchanged during the intervention period. This implies that although the participants performed the exercise training regularly they did not alter their walking or running economy rate and thus, their energy consumption for this work load. However, the reduced fractional oxygen cost of submaximal efforts implies that they have higher energy reserve making daily activities less strenuous. Also, their heart rate during the submaximal effort test decreased significantly at the last test, showing that their relative exhaustion was reduced. In advance of the study, we thought that the oxygen cost of a submaximal effort would also be reduced, due to improved walking or running economy rate. This was, however, not found; however, there was a trend towards lower oxygen uptake at the last time point of testing. We think that more frequent training and/or a longer training period could reduce oxygen uptake at a submaximal load in these children.

To reduce the difficulties caused by limited balance, postural control, and transitions in speed in this group,

Table 3 Exercise test results

\begin{tabular}{|c|c|c|c|c|c|}
\hline & Baseline, T0 & Control test, T1 & p Value, T0-T1* & Follow-up, T2 & p Value, T1-T2* \\
\hline $\mathrm{VO}_{2 \text { peak }}, \mathrm{L} / \mathrm{min}$ & $2.2(1.9-2.7)$ & $2.2(1.8-2.7)$ & 0.48 & $2.4(2.0-3.2)$ & $<0.01$ \\
\hline $\mathrm{VO}_{2 \text { peak }}, \mathrm{mL} / \mathrm{kg} / \mathrm{min}$ & $39.9(30.5-45.0)$ & $37.3(31.0-40.1)$ & 0.48 & $41.0(36.6-48.5)$ & $<0.01$ \\
\hline $\mathrm{VO}_{2 \text { submax }}, \mathrm{mL} / \mathrm{kg} / \mathrm{min}$ & $17.3(15.2-22.1)$ & $17.1(12.6-23.7)$ & NS & $16.4(11.8-21.6)$ & NS \\
\hline$\% \mathrm{VO}_{2 \text { peak }}$ & $50.9(38.1-57.4)$ & $48.8(41.2-63.2)$ & 0.48 & 39.4 (29.7-56.7) & $<0.01$ \\
\hline $\mathrm{HR}_{\text {peak }}, \mathrm{bpm}$ & $193(186-199)$ & $190(181-197)$ & NS & $193(188-196)$ & NS \\
\hline $\mathrm{HR}_{\text {submax }}, \mathrm{bpm}$ & $133(120-145)$ & $127(115-140)$ & 0.32 & 117 (110-134) & 0.02 \\
\hline
\end{tabular}

*Significance levels for post hoc comparisons between the different time points are only reported when the overall comparison was significant. Values are median (IQR). Only children $(n=8)$ who reached $\mathrm{VO}_{2 \text { peak }}$ are included in the analyses of $\mathrm{VO}_{2 \text { peak }}, \% \mathrm{VO}_{2 \text { peak }}$ and $\mathrm{HR}_{\text {peak. }}$. For $\mathrm{VO}_{2 \text { submax }}$ and $\mathrm{HR}_{\text {submax }}$, all children $(\mathrm{n}=10)$ who did not use a body weight support system are included.

$\% \mathrm{VO}_{2 \text { peak, }}$, percentage utilisation of $\mathrm{VO}_{2 \text { peak }}$ at submaximal effort test; $\mathrm{HR}_{\text {peak, }}$, peak heart rate; $\mathrm{HR}_{\text {submax }}$, submaximal heart rate; $\mathrm{NS}$, not significant; $\mathrm{VO}_{2 \text { peak }}$, peak oxygen uptake; $\mathrm{VO}_{2 \text { submax }}$, submaximal oxygen uptake. 
Table 4 Body composition before (T1) and after (T2) the exercise training period

\begin{tabular}{llll}
\hline & T1 $(\mathbf{n}=\mathbf{1 3})$ & T2 $(\mathbf{n}=13)$ & $\mathbf{p ~ V a l u e ~}$ \\
\hline Body weight, $\mathrm{kg}$ & $55.0(44.0-65.5)$ & $57.0(45.0-67.5)$ & 0.08 \\
Height, $\mathrm{m}$ & $1.65(1.55-1.70)$ & $1.65(1.55-1.72)$ & 0.03 \\
BMI, $\mathrm{kg} / \mathrm{m}^{2}$ & $21.0(18.9-24.8)$ & $21.4(19.1-24.5)$ & 0.74 \\
Fat mass, $\mathrm{kg}$ & $15.7(11.5-23.2)$ & $29.9(11.4-23.5)$ & 0.41 \\
Fat mass, \% & $30.9(22.6-36.6)$ & $31.1(38.1-46.5)$ & 0.78 \\
Lean mass, kg & $29.7(37.3-46.1)$ & $67.6(60.5-76.8)$ & 0.05 \\
Lean mass, \% & $66.5(61.0-74.2)$ & $1.20(1.77-2.0)$ & 0.05 \\
Bone mass, kg & $1.31(1.74-1.99)$ & & 0.41 \\
\hline Values are median (IQR). & & &
\end{tabular}

we provided a partial body weight support system. Using this support, 4 of the participants in our study with gross motor impairments corresponding to GMFCS level III or IV, and a minimum walking function managed to walk or run on a treadmill. As these children did not reach a $\mathrm{VO}_{2 \text { peak }}$ at the tests, it is difficult to conclude about a physiological effect of aerobic exercise capacity in these children.

We found no significant changes in body composition after the training intervention, which is in accordance with the few other comparable studies. ${ }^{7}{ }^{14}$ There was, however, a trend towards an increase in lean body mass after the training period. Lean body mass has previously been found to increase after 3 months of HIT in overweight adolescents. ${ }^{5}$

The children did not report any changes in their quality of life, whereas the parents reported improved self-esteem of their children after the training period. As the absolute changes in quality of life outcomes were small and due to multiple comparisons, these results have to be interpreted with caution. Compared with a representative population of typically developing children, ${ }^{15}$ the mean values of the total quality of life and subscale scores were lower in our group-both on the child and parent proxy report. Verschuren et $a l^{16}$ also assessed both aerobic exercise capacity and quality of life before and after an exercise training intervention in children with CP, reporting improvement in basic motor functioning, autonomy, and cognition based on parent evaluation. It is difficult to compare our results with the ones of Verschuren $e t$ al as we used different measures for quality of life.

Considering the physiological limitations that may influence children with CP's performance ability, it is important to take into account their individually experienced effects of activity on pain and fatigue. ${ }^{17}$ Four children withdrew from the study due to lack of motivation. Considering that the exercise regime was strenuous, this number may not be surprising.

\section{Strengths and limitations}

Strengths of the present study are the controlled trial design, as well as the direct measurements of $\mathrm{VO}_{2 \text { peak }}$ and $\mathrm{VO}_{2 \text { submax }}$ according to standardised criteria, and the DXA scanning measurement. It may also be regarded a strength that we included children with GMFCS levels III and IV, as there is limited documentation on the feasibility of aerobic exercise training for these children. Finally, regarding the external validity, it is a strength that HIT is a time-efficient programme, implying that it is possible to fit HIT into a busy schedule for these children.

There are several limitations of the study. Only 8 participants completed the tests for $\mathrm{VO}_{2 \text { peak }}$ according to the standardised criteria, thereby weakening the power of the results. While using a body weight support system or holding on to the treadmill support bars will improve safety during testing and exercise, validity of the measurements for these children are compromised and thus had to be excluded from the $\mathrm{VO}_{2 \text { peak }}$ results. Moreover, as only children who were assumed able to perform the intervention and the testing were invited to participate, we are not able to generalise the findings to all children with CP. Finally, a desire for positive outcome after the intervention period-due to the well-known association between physical activity and health ${ }^{18}$ - may have influenced the parents when completing the quality of life reports.

In conclusion, we found that HIT can be an efficient exercise model for children with CP for improvement in $\mathrm{VO}_{2 \text { peak }}$, thereby reducing the fractional oxygen cost of locomotion for submaximal work. Our study also indicated that HIT can be feasible in this population when individual adjustments were considered. However, more research is needed about the feasibility and cardiovascular effects of HIT in children with CP at all GMFCS levels.

\section{Twitter Follow Trine Moholdt at @trinemoholdt}

Contributors RL contributed to the design of the study, data acquisition, analysis, interpretation, and drafting of the manuscript and approving the final version. TV contributed to the design of the study, analysis, interpretation, and critically revising the manuscript and approving the final version. TL contributed to the design of the study, data acquisition, and critically revising the manuscript and approving the final version. DS and A-KF contributed to the data acquisition, and critically revising the manuscript and approving the final version. TM contributed to the design of the study, data acquisition, analysis, interpretation, and critically revising the manuscript and approving the final version. 
Funding This work was supported by the Norwegian Directorate of Health and the Norwegian Fund for Postgraduate Training in Physiotherapy.

Competing interests None declared.

Patient consent Obtained.

Ethics approval Regional Committee for Medical and Health Research, Trondheim, Norway.

Provenance and peer review Not commissioned; internally peer reviewed.

Data sharing statement No additional data are available.

Open Access This is an Open Access article distributed in accordance with the Creative Commons Attribution Non Commercial (CC BY-NC 4.0) license, which permits others to distribute, remix, adapt, build upon this work noncommercially, and license their derivative works on different terms, provided the original work is properly cited and the use is non-commercial. See: http:// creativecommons.org/licenses/by-nc/4.0/

\section{REFERENCES}

1. Unnithan VB, Dowling JJ, Frost G, et al. Role of cocontraction in the O2 cost of walking in children with cerebral palsy. Med Sci Sports Exerc 1996;28:1498-504.

2. Johnston TE. Energy cost of walking in children with cerebral palsy: relation to the Gross Motor Function Classification System. Dev Med Child Neurol 2004:46:575.

3. Maltais DB, Pierrynowski MR, Galea VA, et al. Physical activity level is associated with the $\mathrm{O} 2$ cost of walking in cerebral palsy. Med Sci Sports Exerc 2005:37:347-53.

4. Hwang $\mathrm{CL}, \mathrm{Wu} \mathrm{YT}$, Chou $\mathrm{CH}$. Effect of aerobic interval training on exercise capacity and metabolic risk factors in people with cardiometabolic disorders: a meta-analysis. J Cardiopulm Rehabil Prev 2011;31:378-85.

5. Tjønna AE, Stølen TO, Bye A, et al. Aerobic interval training reduces cardiovascular risk factors more than a multi treatment approach in overweight adolescents. Clin Sci 2009;116:317-26.
6. Tsoi WS, Zhang LA, Wang WY, et al. Improving quality of life of children with cerebral palsy: a systematic review of clinical trials. Child Care Health Dev 2012;38:21-31.

7. Van den Berg-Emons RJ, Van Baak MA, Speth L, et al. Physical training of school children with spastic cerebral palsy: effects on daily activity, fat mass and fitness. Int $J$ Rehabil Res 1998;21:179-94.

8. Fletcher GF, Balady GJ, Amsterdam EA, et al. Exercise standards for testing and training: a statement for healthcare professionals from the American Heart Association. Circulation 2001;104:1694-740.

9. Borg GA. Psychophysical bases of perceived exertion. Med Sci Sports Exerc 1982;14:377-81.

10. Helseth S, Jozefiak T. The Norwegian version of the KINDL. http://www.kindl.org (accessed 20 Jun 2014).

11. Baquet $\mathrm{G}$, van Praagh $\mathrm{E}$, Berthoin $\mathrm{S}$. Endurance training and aerobic fitness in young people. Sports Med 2003;33:1127-43.

12. Nsenga AL, Shephard RJ, Ahmaidi S. Aerobic training in children with cerebral palsy. Int J Sports Med 2013;34:533-7.

13. Unnithan VB, Katsimanis G, Evangelinou C, et al. Effect of strength and aerobic training in children with cerebral palsy. Med Sci Sports Exerc 2007;39:1902-9.

14. George CL, Oriel KN, Blatt PJ, et al. Impact of a community-based exercise program on children and adolescents with disabilities. $J$ Allied Health 2011;40:e55-60.

15. Jozefiak T, Larsson B, Wichstrøm L, et al. Quality of Life as reported by school children and their parents: a cross-sectional survey. Health Qual Life Outcomes 2008;6:34

16. Verschuren O, Ketelaar M, Gorter JW, et al. Exercise training program in children and adolescents with cerebral palsy: a randomized controlled trial. Arch Pediatr Adolesc Med 2007;161:1075-81.

17. Brunton LK, Bartlett DJ. The bodily experience of cerebral palsy: a journey to self-awareness. Disabil Rehabil 2013;35:1981-90.

18. Leon AS, Franklin BA, Costa F, et al. Cardiac rehabilitation and secondary prevention of coronary heart disease: an American Heart Association scientific statement from the Council on Clinical Cardiology (Subcommittee on Exercise, Cardiac Rehabilitation, and Prevention) and the Council on Nutrition, Physical Activity, and Metabolism (Subcommittee on Physical Activity), in collaboration with the American Association of Cardiovascular and Pulmonary Rehabilitation. Circulation 2005;111:369-76. 